\title{
Revision operations after previous stapes surgery for persisting hearing loss
}

\author{
Skrivan J, Cada Z, Kluh J, Boucek J, Profant O, Betka J \\ Department of Otorhinolaryngology and Head and Neck Surgery, 1st Faculty of Medicine, Charles University, \\ Prague, and Faculty Hospital Motol, Postgraduate Medical School, Czech Republic. zdenek.cada@lf1.cuni.cz
}

\begin{abstract}
Objectives: The aim of the study was to find out the reasons of the recurrent or persisting hearing loss after previous stapes surgery indicated for otosclerosis.

Background: Revision stapes surgery is a relatively safe surgical method. Recurrent or persisting conductive hearing loss is commonly caused by prosthesis dislocation and adhesions in the oval window. Hearing loss is directly proportional to the number of previous operations.

Method: Retrospective analysis of 48 patients after revision stapes surgery was done over a period of 4 years (2005-2008). Improvement of the hearing and the reasons of a previous surgery failure were studied.

Results: Results were compared to the other studies. The main reason of the failed surgery was adhesions and dislocation of the prosthesis. The mean postoperative air-bone gap was $12.0 \mathrm{~dB}$. A mean postoperative air-bone gap closure within $10 \mathrm{~dB}$ occurred in 24 cases (55.8\%), between 11-20 dB occurred in 11 cases (25.6\%) and above $20 \mathrm{~dB}$ in 8 cases (18.6\%). The original prosthesis was replaced with a new one in $41(95.3 \%)$ cases. In 2 cases $(4.7 \%)$, previous prostheses were left in place and fixed by a ionomer glass cement to the long process of incus. Conclusion: Revision stapes surgery is a relatively safe surgical procedure allowing to improve hearing. The number of previous stapes surgery deteriorates hearing $(\mathrm{p}<0.05)$ (Tab. 4, Ref. 20). Text in PDF www.elis.sk. Key words: revision stapes surgery, otosclerosis.
\end{abstract}

Otosclerosis is the primary disease affecting the otic capsula, which causes a progressive hearing loss (1). Treatment includes hearing aids and surgery. Surgical solution is represented by stapedectomy and stapedotomy. The principle of the surgical procedure is a total or partial removal of stapes and its replacement by a titanium prosthesis (2). Best functional results are reached in a primary surgery. Failure of a primary procedure demands revision surgery in the majority of cases. Hearing results after revision surgical procedures are worse compared to the primary surgeries and are dependent on the cause for a revision surgery and on the number of previous stapes surgeries. Moreover, revision surgery is connected with higher risks, as profound sensorineual hearing loss, dizziness, etc. $(3,4,5)$. It is generally known that the rate of successful surgical procedure, evaluated as closure of air-bone gap less than $10 \mathrm{~dB}$ ranges between $20-85 \%(6,7)$. The most common cause of a previous failed procedure is a prosthesis displacement, while other reasons like fibrous adhesion, footplate obliteration, short prothesis etc., are not so frequent $(8,10)$.

Department of Otorhinolaryngology and Head and Neck Surgery, 1stFaculty of Medicine, Charles University, Prague, and Faculty Hospital Motol, Postgraduate Medical School, Czech Republic

Address for correspondence: $\mathrm{Z}$. Cada, MD, PhD, Department of Otorhinolaryngology and Head and Neck Surgery, 1st Faculty of Medicine Charles University in Prague Faculty Hospital Motol, Postgraduate Medical School, V Uvalu 84, CZ-150 06 Praha 5, Czech Republic. Fax: +420.2 .24965770$

Acknowledgement: This research was supported by the grants No. 260510 of the Charles University in Prague and IGA MZČR NT/11543-6.
Hearing restoration depends especially on a primary surgical technique, technique used during revision procedure and also on the number of previous surgical interventions (9).

Retrospective analysis was realized on 343 patients who underwent a stapes surgery for otosclerosis in the Department of Otorhinolaryngology and Head and Neck Surgery of the 1stFaculty of Medicine Charles University in Prague, Faculty Hospital Motol, in the years 2005-2008. From this group of patients, 48 underwent revision surgery.

\section{Methods}

In the study, we have evaluated 43 patients (10 males, 33 females,) who underwent revision stapes surgery in the years 2005-2008. All patients were preoperatively examined and indicated for surgery in the ENT department. No patient suffered from a profound sensoneurinal hearing loss and vertigo before the revision. All patients were examined by otomicroscopy and pure tone audiometry. The mean age during the first revision surgery was 45.1 years (range 21-74). The indication for revision operation was a conductive hearing loss over $20 \mathrm{~dB}$ in main frequencies $(500,1000,2000,4000 \mathrm{~Hz})$. The mean preoperative air-bone gap was measured as the difference between preoperative air-conductive threshold and preoperative bone-conductive threshold at frequences 250, 500, 1000, 2000 and $4000 \mathrm{~Hz}$. Number of previous revisions is summarized in the Table 1.

The revision technique was performed under a local or general anaesthesia. Endaural approach was performed in all cases. 
Tab. 1. Number of previous revisions.

\begin{tabular}{lcc}
\hline $1 \mathrm{x}$ & 31 & $73 \%$ \\
\hline $2 \mathrm{x}$ & 5 & $12 \%$ \\
\hline $3 \mathrm{x}$ & 4 & $9 \%$ \\
\hline $4 \mathrm{x}$ & 1 & $2 \%$ \\
\hline $11 \mathrm{x}$ & 1 & $2 \%$ \\
\hline Unknown & 1 & $2 \%$ \\
\hline Total & 43 & $100 \%$ \\
\hline
\end{tabular}

Tab. 2. Mean preoperative air-bone gap (MPABG) and postoperative air bone gap (MPostABG).

\begin{tabular}{lcccccc}
\hline & $\begin{array}{c}250 \\
\mathrm{~Hz}\end{array}$ & $\begin{array}{c}500 \\
\mathrm{~Hz}\end{array}$ & $\begin{array}{c}1000 \\
\mathrm{~Hz}\end{array}$ & $\begin{array}{c}2000 \\
\mathrm{~Hz}\end{array}$ & $\begin{array}{c}4000 \\
\mathrm{~Hz}\end{array}$ & $\begin{array}{c}\text { Average } \\
\text { in all } \\
\text { frequencies }\end{array}$ \\
\hline MPreABG $(\mathrm{dB})$ & 45,9 & 34,3 & 30,4 & 14 & 22,5 & 29,4 \\
MPostABG $(\mathrm{dB})$ & 23,4 & 15 & 11,4 & 3,14 & 6,9 & 11,6 \\
\hline
\end{tabular}

Tab. 3. Frequency of air bone gap closure within $10 \mathrm{~dB}, 11-20 \mathrm{~dB}$ and more than $20 \mathrm{~dB}$.

\begin{tabular}{lcc}
\hline range $(\mathrm{dB})$ & No. & $\%$ \\
\hline$<10$ & 24 & 55,8 \\
$11-20$ & 11 & 25,6 \\
$>20$ & 8 & 18,6 \\
\hline Total & 43 & 100 \\
\hline
\end{tabular}

After exposing of the middle ear, the intra-operative findings were examined to evaluate the reasons of a previous surgery failure.

Postoperative audiological testing was performed and evaluated one year after the surgery. The mean pre and postoperative air-bone gap was calculated as the difference between the mean air-conductive threshold, and mean bone-conductive threshold at frequencies of 250, 500, 1000, 2000 and $4000 \mathrm{~Hz}$. Air-bone gap closure was calculated as the difference between preoperative airbone gap and postoperative air bone gap (Tab. 2). Number of airbone gap closure within $10 \mathrm{~dB}, 20 \mathrm{~dB}$ and more than $20 \mathrm{~dB}$ was analysed (Tab. 3). The association between number of previous surgeries and postoperative air-bone gaps was statistically analyzed using $\chi^{2}$ and student's t test. $\mathrm{p}$ value was calculated.

\section{Results}

During the period 2005 to 2008,343 patients underwent a stapes surgery indicated for otosclerosis in the ENT department. $48(14 \%)$ patients underwent revision stapes surgery because of a previous surgery failure. Five patients were excluded from the study because of the lack information in hospital documentation including one patient with a postoperative sensoneurinal hearing deafness. Revision operations were done on 23 left ears (53.5\%) and 20 right ears $(46.5 \%)$. Thirty-one cases $(72.1 \%)$ were revised once, five cases $(11.6 \%)$ required 2 revisions, four cases $(9.3 \%)$ required 3 revisions, one case $(2.3 \%)$ was revised four times, one case was revised eleven times and at one case the number of previous revision surgeries was unknown because of the lack of the information from patient and documentation (Tab. 1). The main reasons of repeated previous surgery were especially dislocation of prostheses and adhesions around the oval window.
Tab. 4. Intra-operative findings.

\begin{tabular}{lcc}
\hline Intra-operative findings & No. & $\%$ \\
\hline Adhesions in the oval window & 12 & 27,9 \\
Prosthesis dislocation & 11 & 25,6 \\
Long process of incus necrosis & 7 & 16,3 \\
Fixation of incus or malleus & 3 & 7 \\
Missed incus and suprastructures & 1 & 2,3 \\
Short prosthesis & 1 & 2,3 \\
Previous mobilisation & 8 & 18,6 \\
\hline TOTAL & 43 & 100 \\
\hline
\end{tabular}

Audiological data are summarized in the Table 2. The table demonstrates mean pre-operative air-bone gap and mean postoperative air-bone gap on frequencies 250, 500, 1000, 2000 and $4000 \mathrm{~Hz}$ and average in all frequencies. The results show improvement of hearing gain in all frequences. The mean postoperative air-bone gap was $11.6 \mathrm{~dB}$. The best hearing results were obtained in the frequencies 500, 1000, 2000 and $4000 \mathrm{~Hz}$. Table 3 demonstrates air-bone gap closure within $10 \mathrm{~dB}, 20 \mathrm{~dB}$ and more than $20 \mathrm{~dB}$ after revision surgery. There were twenty-four cases $(55.8 \%)$ with air-bone closure within $10 \mathrm{~dB}$, eleven cases $(25.6 \%)$ with postoperative air-bone gap closure within $20 \mathrm{~dB}$ and eight cases (18.6\%) with postoperative air-bone gap closure more than $20 \mathrm{~dB}$.

In one patient, sensoneurinal deafness occurred after the fourth revision surgery. This patient was not included into the audiological statistical analysis.

The most common cause of a previous surgical failure were adhesions in the oval window (12 cases, $27.9 \%$ ) and prosthesis dislocation (11 cases, $25.6 \%$ ), long process of incus necrosis occurred in 7 cases $(16.3 \%)$, fixation of incus or malleus occurred in 3 cases $(7.0 \%)$, in $1(2.3 \%)$ patient the incus was missing, in one case $(2.3 \%)$ the prosthesis was too short, 8 patients $(18.6 \%)$ were after previous mobilisation and 3 of these patient had fracture of dorsal stapes crus (Tab. 4).

During revision surgeries original prosthesis were replaced in 41 cases $(95.3 \%)$ mostly by the Piston prosthesis (33 cases, $76.7 \%$ ), in 7 cases $(16.3 \%$ ) by the Schuknecht wire and fat prosthesis. In one patient $(2.3 \%)$, the original Schuknecht prosthesis was replaced by TORP prosthesis because the malleus and incus were fixed and prothesis was dislocated and too short and refixation by original prostheses or piston was impossible. In 2 patients $(4.7 \%)$, the Ionomer glass cementum was used to fixation of original Schuknecht prosthesis to bones.

The number of previous stapes surgeries deteriorates hearing $(\mathrm{p}<0.05)$.

\section{Discussion}

Hearing loss is the main reason of revision surgery after stapes surgery. The incidence of hearing loss after revision surgery ranges from 24 to $80 \%$ (10). The sensoneurinal hearing loss occurs in 3 to $20 \%$ after this type surgery (11). During the period 2005-2008, 343 patients underwent stapes surgery and 48 (14\%) of them underwent revision stapes surgery because of hearing loss in our study. There was one patient with profound sensoneurinal 
$442-444$

hearing loss in our study. This patient was excluded from audiological analysis.

The success of revision surgery is generally confirmed by closure of the post-operative air-bone gap within $10 \mathrm{~dB}$. Closure of air-bone gap after stapes surgery within $10 \mathrm{~dB}$ is described by many authors in the range from $25-80 \%$ (12). In our study, closure of air-bone gap within $10 \mathrm{~dB}$ was observed in 24 cases (55.8 \%), between $11-20 \mathrm{~dB}$ in 11 cases $(25.6 \%)$ and closure of post-operative air-bone gap for values above $20 \mathrm{~dB}$ was observed in 8 patients $(18.6 \%)$.

The most common cause of stapes revision surgery was fibrous adhesions in the oval window, which is contrary to published data from other authors where the most frequent reason of previous failure stapes surgery was displacement of original prosthesis (range $25-80 \%)(6,8,10,17)$.

The presence of fibrous adhesions was found in 12 patients $(27.9 \%)$ This result is compared to literature where the incidence of fibrosis is published to range from 2 to $38 \%(10,14)$.

There are several theories explaining the formation of fibrous tissues. One of them is that fibrous adhesion tissue in the oval window is a result of a mucous irritation from postoperative inflammation or it is a reaction to a foreign-material $(10,15)$.

The second most common failure of a stapes surgery in our study was a displacement of the prosthesis. Displacement of original prosthesis was present in 11 cases $(25.6 \%)$. There were several reasons for displacement of the original prosthesis. The most frequent reason for prosthesis displacement was loosening of the prosthesis hook from the long process of incus.

The third common failure of stapes surgery was necrosis of long incus process which occurred in 7 cases $(16.3 \%)$. Avascular erosion from the pressure of prothesis on mucosa is the most common reason of prothesis dislocation and the incidence in literature is described from $5 \%$ to $31 \%(13,17,18,19,20)$. In our series, 41 prostheses were exchanged by a new one and in two cases the Ionomer glass cementum was used for a better fixation.

Fixation of malleus, missing incus or suprastuctures, short prosthesis and previous failure stapes mobilisation with or without fracture of dorsal stapes crus were not so frequent reason of previous failure stapes surgery. In all these cases, new prosthesis was inserted during the revision stapes surgery.

\section{References}

1. Markou K, Goudakos J. An overview of the etiology of otosclerosis. Eur Arch Otorhinolaryngol 2009; 266: 25-35.

2. Shea JJ. Fenestration of the oval window. Ann Otol Rhinol Laryngol 1958; 67: 932-951.

3. Sheehy JL, Nelson RA, House HP. Stapes surgery at the otologic medical group. Am J Otol 1979; 1: 22-26.

4. Elonka DR, Derlacki EL, Harrison WH. Stapes prosthesis comparison. Otolaryngol Head Neck Surg 1982; 90: 263-265.

5. Causse JB, Causse JR. Minimizing cochlear loss during and after stapedectomy. Otolaryngol Clin North Am 1982; 15: 813-835.

6. Lippy WH, Schuring AG, Ziv M. Stapedectomy revision. Am J Otol 1980; 2: 15-21.

7. Palva T, Ramsay H. Revision stapes surgery for otosclerosis. Acta Otolaryngol 1990; 110: 416-420.

8. Langman AW, Lindeman RC. Revision Stapedectomy. Laryngoscope 1993; 103: 954-958.

9. Lippy WH, Battista RA, Bernholz $L$ et al. Twenty-year review of revision stapedectomy. Otol Neurotol 2003; 24: 43-47.

10. Puxeddu R, Ledda GP, Pelagatti CL, Salis G, Agus G, Puxeddu P. Revision stapes surgery for reccurent transmissional hearing loss after stapedectomy and stapedotomy for otosclerosis. Acta Othorhinolaryngol Ital 2005; 25: 347-352.

11. Lesinski SG. Revision stapedectomy. Otology-neurotology 2003; 11 : 347-354.

12. Gros A, Vatovec J, Žargi M, Jenko K. Success rate in revision stapes surgery for otosclerosis. Otol Neurotol 2005; 26: 1143-1148.

13. Krieger WL, Lippy HW, Schuring GA, Rizer MF. Revision stapedectomy for incus erosion: Long-term hearing. Otorynolaryngology-Head Neck Surgery 2005; 119: 370-373.

14. Fish U, Acar GO, Huber AM. Malleostapedotomy in revision surgery for otosclerosis. Otol Neurotol 2001; 22: 776-785.

15. Cokkeser Y, Naguib M, Saleh E, Landolfi M, Russo A, Sanna M. Revision stapes surgery: a critical evaluation. Otolaryngol Head Neck Surg 1994; 111: 473-477.

16. Crabtree JA, Britton BH, Powers WH. An evaluation of revision. Laryngoscope 1980; 90: 224-227.

17. Sheehy JL, Nelson RA, House HP. Revision stapedectomy: review of 258 cases. Laryngoscope 1981; 91: 43-50.

18. Glasscock ME, McKennen KX, Levine SC. Revision stapedectomy surgery. Otolaryngol Head Neck Surg 1987; 96: 141-148.

19. Pearman K, Dawes JD. Poststapedectomy conductive deafness and results of revision surgery. J Laryngol Otol 1982; 96: 405-410.

20. Farrior J, Sutherland A. Revision stapes surgery. Laryngoscope 1991; 101: $1155-1160$. 